\title{
Is Organic Labelling Enough? Information Disclosure as Policy Instrument to Empower Consumer Choices
}

\author{
Jing Zhang \\ Clark University \\ jizhang@clarku.edu
}

\author{
Lin Boldt \\ Clark University \\ $\underline{\text { lboldt@,clarku.edu }}$
}

\begin{abstract}
Governments have been advocating for an open approach to encourage private sector disclosing relevant information in order to create more efficient market. However, it is not always clear what information are needed by consumers. Policy makers need to develop measures that help decide what information should be disclosed and whether a disclosure should be mandated. In this research, we focus on information disclosure in organic products, where consumers find the complex organic labeling hard to understand. Through two studies, we show that feed origin makes a significant difference in consumers' choice; and sellers with feed from nonUSA countries would be motivated to disguise the information on feed origin. We propose a way to implement "smart" information disclosure that can effectively distinguish USA feed from feed with undisclosed origin, which enables the feed from USA to claim a higher price premium. Our findings have policy implications for organic product disclosure.
\end{abstract}

\section{Introduction}

An efficient market calls for a free flow of information between sellers and buyers. If properly designed, information disclosure should promote autonomy and quality of individual decision making, increase efficiency and help prevent market failure resulting from incomplete and asymmetric information coupled with misaligned incentives [1-3]. However, inappropriate information disclosure fails to improve the quality of consumer decisions $[1,4,5]$. When directly asked, consumers say they want to know virtually everything about their choices [4]. In reality, one of the most ubiquitous problems is the information overload effect. Consumers are constantly confronted with complex instructions and fine prints, yet they have limited capacity to attend the information presented. Too much disclosure can be counterproductive when it distracts from more important information [1]. On the other hand, not disclosing the relevant information would introduce bias to people's decision making. Moreover, people tend to pay even less attention to the absence of information than to its presence, even when both are equally informative [6].

Policymakers need to choose the most important and relevant information, and provide guidance for information to be disclosed in simple and easy to digest form. It is not an easy task to decide what information should be disclosed and how the information should be presented to consumers. We focus on organic food industry because of the information asymmetry between sellers and buyers for this product category [7]. It is very hard, if not impossible, for consumers to detect the organic characteristics and quality even after purchase and use of the product [8]. Consumers typically rely on information cues such as organic certification and labels to make a judgement on the quality, while the organic certification process is criticized for lacking rigor and adequate transparency [9].

The market of organic food has expanded drastically and the US domestic organic production is not keeping up with the demand. According to the Organic Trade Association, sales of organic food and non-food products reach another record in 2014, totaling \$39.1 billion [10]. Domestic organic food production has expanded 240 percent between 2002 and 2011, compared with 3 percent for non-organic food production [11]. The growing demand for organics, coupled with the near-total reliance by U.S. farmers on genetically modified corn and soybeans, is driving a surge in imports from other nations where crops largely are free of bioengineering ${ }^{1}$. Take organic eggs as an example, America's farmers are not growing enough organic corn and soybeans to feed the country's organic animals. In 2014, the U.S. gets more than half of its organic soybeans from abroad. The biggest suppliers are China and India ${ }^{2}$.

\footnotetext{
1 "U.S. Forced to Import Corn as Shoppers Demand Organic Food," $<$ http://www.bloomberg.com/news/articles/2015-04-15/romaniancorn-imports-to-u-s-surge-as-shoppers-demand-organic $>$

2 "Chickens That Lay Organic Eggs Eat Imported Food, And It's Pricey,"

$<$ http://www.npr.org/sections/thesalt/2014/02/26/283112526/chicken s-laying-organic-eggs-eat-imported-food-and-its-pricey>
} 
In organic food category, country of feed origin is a manifestation of the information asymmetry between sellers and buyers. Although USDA's Food Safety and Inspection Service (FSIS) requires country of origin being disclosed on the labeling of most food products, no regulation is found to mandate the disclosure of the feed origin ${ }^{3}$. In another word, if an egg is laid in the US, the country of origin of the egg is USA. However, if the hen that laid the egg ate imported organic feed, while the sellers are aware of the feed origin of their product and the potential problems with certification process of organic food in certain countries, they may not be motivated to disclosure feed origin. Whether country of feed origin is an important purchase criterion for consumers should be of interest to policy makers, because this may serve as the basis for deciding whether feed origin should be a mandatory disclosure. This question could also be of interest to suppliers in that they are more informed of whether labeling feed origin on their products could enable them to charge price premium. This would especially be of interest to third party platforms, because it helps them design the system that match the needs of consumers.

In this research, we investigate the following three research questions. 1) Is the disclosure of country of feed origin necessary for consumers in the market for organic food? 2) Can a price premium be claimed on organic food from countries with a more stringent legal framework? 3) What are the effects on consumer choices and price premium if the disclosure of feed origin is mandated, or made a salient attributes through "smart" disclosure?

We conducted two studies using online subjects. Organic egg is chosen as the focal category. Through a conjoint study and using a Hierarchical Bayes choice model, we find that information on feed origin is an important factor in people's purchase decision of eggs, more so than USDA organic certification label. This study proposes an approach that can help policy makers and private sectors decide what information firms should disclose, and assess the impact on marketing implication of the policy. The findings have implications for smart disclosure policy which aims to present information in an accessible way, in order to empower consumer decision. This article contributes to the burgeoning literature on the information regulation and marketing of sustainable products. To authors' knowledge, we are the first to explore the importance and disclosure of country of feed origin for organic food products, which has important implications for

\footnotetext{
${ }^{3}$ http://www.fsis.usda.gov/shared/PDF/Labeling_Requiremen ts_Guide.pdf
}

policy makers, marketers and information sharing platforms.

\section{Literature review}

In this section, we review the literature on the public policy and consumer motivation of organic products. On the regulatory aspect, we focus on the policy environment for organic food, highlighting the standards that govern organic production and quality control. On the demand side, we discuss consumer motivation to purchase organic food, the information gap between sellers and buyers of organic products, and the reliance of information cues for consumers to judge the quality of organic products.

\subsection{Organic Food Policy}

Before the establishment of a federal policy framework for organic food, a patchwork of industry standards and state organic food laws had emerged since 1973 to govern the U.S. organic food industry [12]. Responding to the call from organic farmers, certification agents and organic trade association, a national Organic Food Production Act of 1990 (OFPA) was enacted by Congress to harmonize the divergent standards. OFPA delegate the task of regulating organic production, handling and labeling to the U.S. Department of Agriculture (USDA), which promulgated National Organic Program in 2002 as binding rules to enforce OFPA. The purpose of these federal regulations is to establish and implement standards to govern the organic food industry and ensure consumers that agriculture product marketed with the organic label met uniform and consistent standards [9].

NOP made specific requirements for organic crop production, livestock farming, and the handling of organic products ${ }^{4}$. To qualify as organic egg, the poultry need to be fed organic feed. Organic feed are produced on farms that practice organic farming, which requires that crops must be produced on land that are free of synthetic pesticide, herbicides and fertilizer for three years before harvest and sufficient buffer zone exists to reduce contamination from surrounding lands [13]. The USDA certifies organic products according to these guidelines. The way by which the standards are ensured is through a certification process. USDA however does not conduct field inspections. Instead, it accredits certification agents to review and certify organic farms and processor in accordance to the standard set up in the OFPA [9]. Currently, around 80 agents received USDA's authorization to certify farms and businesses.

\footnotetext{
47 CFR Part 205, Subpart C - Organic Production and Handling Requirements
} 
Among them, many USDA-accredited certifying agents are outside of US and most are allowed to certify farms and businesses around the world [14].

This certification system is not free from problems. One of the major issue is that certifying agents are private entities that on the one hand have a vested interests to maintain their creditability by enforcing OFPA standards, and on the other hand are paid by the applicants and need to compete for the market to ensure the viability. An operation that may has non-compliance issues may shop around for a more lenient agent instead of addressing the risks and problems, which essentially lower the rigor of the organic standards. More importantly, the NOP regulations ignored the original intent of the OPFA that requires periodic residue testing by certifying agents. Instead, the NOP regulations do not mandate residue testing and deferred the decision to state officials and certifying agents on whether to perform such testing. Further, the state officials and certifying agents must bear the costs of the tests. For a market where an applicant can freely choose certifying agents and the agents have little incentives to perform the necessary testing for fear of losing business, the NOP regulation have effectively eliminated the residue testing requirements [9]. Another critique of the current certification system is that the NOP have not been effective in regulating foreign certifying agents.

\subsection{Information Asymmetry and Smart Disclosure Policy}

Consumers are generally not satisfied with the availability of information that can guide their purchase decision [15], and arguably, they are especially in a disadvantaged position to judge the potential compromises that the organic certification system creates. Information asymmetry, the gap of information with regard to the quality of organic products between consumers and producers, are expressly severe because of the nature of the products. In making choices for products, consumer typically relies on the dominant quality attributes, namely search, experience, credence and potemkin attributes [16]. A search attribute, such as freshness or appearance, is known before the purchase and consumers have the ability to examine it. Experience attributes, such as taste, are known after the consumption of the product. Credence attributes, such as nutrition or contamination, are difficult to be observed by consumers, but they can rely on third parties for quality assurance. However, as noted earlier, organic food can reach the market without any residue testing, which is a failure to ensure the credence attributes. Potemkin attributes are processrelated qualities that cannot be proved and controlled through laboratory analyses by either the consumers or external institutions. Only close monitoring of the internal production process would have a chance to detect fraud and mislabeling [16]. Organic claim with the primary goal to "optimize the health and productivity of interdependent communities of soil life, plants, animals and people" [17] are essentially potemkin attributes that are especially susceptible to the lack of quality information on the side of consumers. The NOP is process oriented regulation, and the organic certification system is designed to closely monitor the production process. However, weaknesses of the NOP regulation give rise to conditions for fraud and opportunistic behaviors in such markets. This is especially troublesome for organics imported from some developing countries bearing "USDA Organic" seals, where the legal framework is weak and corruptions are rampant [9].

Smart disclosure is a policy initiative promoted by the US government to use information disclosure as a regulatory approach to create more transparent, efficient market for goods and services (Executive Office of the President National Science and Technology Council, 2013). The basic premise of smart disclosure is giving more power to the general public by transferring control of personal data from the hands of corporate interests to the public [18, 19]. Recently, smart disclosure policy has been applied in various sectors such as education, energy and environment, health care, finance, food and nutrition, safety, telecommunication, transportation and others. Proponents of smart disclosure argue that such policy can also be used to help consumers in making informed decisions by minimizing behavioral biases resulting from information overload and aversion to complexity that consequently cause consumers to make undesirable choices [20]. There is, however, a need for public and private sector to connect information disclosed with consumers' motivations in order to be effective in empowering consumer decision making.

\subsection{Consumer Motivation and Demands for Information}

Consumers buy organic versus conventional products for several reasons. Prior research have shown that they are motivated by the perceived health and nutrition benefits of organic products, environmental concerns, and ethical considerations of animal welfare [21]. Organic food is generally regarded as more nutritious and safer than convention products [22]. Recent expansion of organic food market has also been seen as the results of heightened awareness of the impact of food systems on environment [23]. Such consumers are willing to pay a price premium for the 
additional benefits consuming the organic products [24].

However, these values are not attributes that can be directly observed by consumers. Instead, they rely on various information cues on the label when evaluating products under uncertainty. Labels or organic claims are widely used to transmit important quality information to consumers [25]. Organic labeling has been observed to be associated with a higher level of perceived healthfulness, hedonism, environmental friendliness and food safety [26, 27]. Since organic eggs are credence and potemkin products, labels bearing organic certification elicit certain level of confidence of the values acquired through consuming organic egg.

Not all organic labels, however, elicit the same level of trust. In general, a third-party certification schedule is considered to be more trustworthy than producers' or retailers' private labelling scheme [28, 29]. Label agency makes a difference to consumers' perception and willingness to pay. For example, in Switzerland, organic consumers were willing to pay a higher premiums for products with the Bio Suisses label, a label backed by the farmers' umbrella organization, compared to products with other organic label [30]. Consumers in Denmark and Czech Reblic are willing to pay the highest price premium for governmental logo [31]. The reputation and brand image of the label agency lend creditability to the label, and enhance the level of consumer trust. Although consumers are not willing to automatically assume fidelity of quality assurance behind of every label, they may place greater level of trust over the logos backed by ethical practices and stringent legal requirements [20]. In the US, USDA organic has been an established logo with high level of consumer awareness and positive perception of the certification scheme behind it, consumers are responding to USDA organic milk more positively then generic organic labels [32]. In addition, animal welfare are cited as a major concern for consumers purchasing organic, and flock size is often listed by organic egg producers and organic product information sharing organizations (e.g., The Cornucopia Institute) as an indicator for animal welfare.

The extant literature has not systematically examined the information cues other than organic labels that consumers would rely on to assess the quality of organic products. The marketing literature has documented country of origin as one of the extrinsic information cues to help consumers detect the quality of products. However, there is a lack of empirical evidence in the literature on whether consumer reacts to the information on organic products' feed origin. Given the weakness of organic certification process and accountability in certain countries, and yet no regulation to mandate the disclosure of the feed origin, policy makers may want to know if it is a potentially important decision making factor in purchasing organic food for consumers and if its disclosure should be made mandatory. Similarly, certain organic sellers may benefit from disclosing the feed origin, if it is indeed valued by consumers and the sellers can charge a price premium labeling feed from the US.

\section{Empirical Study}

\subsection{Study 1}

Study Design. The purpose of Study 1 is to address the first two research questions. A conjoint approach was used to elicit consumer preferences. Conjoint analysis has been applied in marketing field as a major set of techniques for measuring buyers' tradeoffs among multiattributed products and services [33]. It presents consumers with various combinations of product attributes and statistically estimates the effects of those attributes on choice. Conjoint analysis has been widely used in new product design and marketing mix decisions.

We collected data using a Qualtrics webbased survey and a nationwide sample recruited from an online panel. A total of 130 respondents participated in this study. The respondents were screened to be US citizens or permanent residents and they must be over 18 years old. Most of the participants have purchased organic food $(95.3 \%)$ and majority have bought organic eggs $(66.7 \%)$. On the introduction screen, we informed participants that the purpose of our study was to understand how consumers purchase eggs. They then went through 16 choice-based conjoint tasks. The attributes and levels used in the conjoint exercises are shown in Table 1. Scholars have looked into consumer preference on organic eggs in terms of price, organic label, USDA label and cage-free [32]. In our conjoint design, we included feed origin, our focal point of interest, together with attributes from the literature. The attribute levels were designed to be consistent with the market situation. In market place, organic and nonorganic eggs have different price points. In our study, organic eggs are priced at $\$ 4.99, \$ 3.99$ or $\$ 2.99$ and non-organic eggs are priced at $\$ 3.99, \$ 2.99$ or $\$ 1.99$. USDA is only associated with organic eggs and they are typically sold at a premium in the market place. In the study, USDA organic eggs are priced at $\$ 4.99$ or \$3.99. Feed origin has a level "Not disclosed". In study 1 , we left this attribute level empty in the choice exercises. This design is consistent with the market place situation, where the feed origin is typically not 
disclosed on the package. Table 2 shows an example of a conjoint choice set. Respondents were told to choose the eggs they prefer the most assuming all the options are dozen eggs and are identical on other attributes. They were also given the option of not choosing.

Table 1: Conjoint Design, Attributes and Levels

\begin{tabular}{|c|c|c|c|c|}
\hline Attributes & Levels & & & \\
\hline $\begin{array}{l}\text { Price per } \\
\text { dozen }\end{array}$ & $\$ 1.99$ & $\$ 2.99$ & $\$ 3.99$ & $\$ 4.99$ \\
\hline $\begin{array}{l}\text { Organic } \\
\text { feed }\end{array}$ & $\begin{array}{l}\text { Organic } \\
\text { feed }\end{array}$ & $\begin{array}{l}\text { Non- } \\
\text { organic } \\
\text { feed }\end{array}$ & & \\
\hline Cage-free & $\begin{array}{l}\text { Cage- } \\
\text { free }\end{array}$ & In cages & & \\
\hline USDA & USDA & $\begin{array}{l}\text { Non- } \\
\text { USDA }\end{array}$ & & \\
\hline Flock size & $<10000$ & $\begin{array}{l}10,000- \\
100,000\end{array}$ & $\begin{array}{l}100,000- \\
250,000\end{array}$ & $\begin{array}{l}\text { Not } \\
\text { disclosed }\end{array}$ \\
\hline Feed origin & USA & China & Argentina & $\begin{array}{l}\text { Not } \\
\text { disclosed }\end{array}$ \\
\hline
\end{tabular}

Table 2: An Example of the Conjoint Exercise

\begin{tabular}{|l|l|l|}
\hline $\boldsymbol{E g} \boldsymbol{A} \boldsymbol{E}$ & $\boldsymbol{E g} \boldsymbol{B}$ & $\boldsymbol{E g} \boldsymbol{C}$ \\
\hline $\begin{array}{l}\text { Price: } \\
\text { \$3.99/dozen }\end{array}$ & $\begin{array}{l}\text { Price: } \\
\text { \$4.99/dozen }\end{array}$ & $\begin{array}{l}\text { Price: } \\
\text { \$2.99/dozen }\end{array}$ \\
\hline Organic feed & Organic feed & Non organic feed \\
\hline $\begin{array}{l}\text { Hens are raised in } \\
\text { cages }\end{array}$ & $\begin{array}{l}\text { Hens are raised } \\
\text { cage free }\end{array}$ & $\begin{array}{l}\text { Hens are raised } \\
\text { cage free }\end{array}$ \\
\hline $\begin{array}{l}\text { No USDA } \\
\text { Organic } \\
\text { certification }\end{array}$ & $\begin{array}{l}\text { USDA Organic } \\
\text { certification }\end{array}$ & $\begin{array}{l}\text { No USDA } \\
\text { Organic } \\
\text { certification }\end{array}$ \\
\hline $\begin{array}{l}\text { Size: } 10,000- \\
100,000 \text { birds }\end{array}$ & $\begin{array}{l}\text { Size: } 100,000- \\
250,000 \text { birds }\end{array}$ & \\
\hline & $\begin{array}{l}\text { Feed comes } \\
\text { from Argentina }\end{array}$ & $\begin{array}{l}\text { Feed comes from } \\
\text { USA }\end{array}$ \\
\hline
\end{tabular}

Model and Results.

We use hierarchical Bayes logit model to analyze the conjoint data. Consumer i's utility from choosing option $j$ can be written as:

$$
\begin{aligned}
u_{i j}= & \beta_{i, 0}+\beta_{i, \text { OriginND }} \text { OriginND }+\beta_{i, \text { OriginC OriginC }}+\beta_{i, \text { OriginA }} \text { OriginA } \\
& +\beta_{i, \text { logprice }} \text { Price }+\beta_{i, \text { Organic }} \text { Organic }+\beta_{i, \text { Cagefree }} \text { CageFree } \\
& +\beta_{i, U S D A} U S D A+\beta_{i, \text { SizeND }} \text { SizeND }+\beta_{i, \text { SizeSn }} \text { SizeSm }+\varepsilon_{\mathrm{ij}}
\end{aligned}
$$

where

OriginND = dummy variable, taking the value of 1 if feed origin is not disclosed and 0 if otherwise;

OriginC = dummy variable, taking the value of 1 if feed origin is China and 0 if otherwise;

OriginA = dummy variable, taking the value of 1 if feed origin is Argentina and 0 if otherwise;

Price $\quad=$ price per dozen;
Organic = dummy variable, taking the value of 1 if feed is organic feed and 0 if otherwise;

CageFree $=$ dummy variable, taking the value of 1 if eggs are cage-free 0 if otherwise;

USDA = dummy variable, taking the value of 1 if eggs are USDA organic and 0 if otherwise;

SizeND = dummy variable, taking the value of 1 if hens are raised in houses with bird size not disclosed and 0 if otherwise;

SizeSm = dummy variable, taking the value of 1 if hens are raised in houses with less than 10,000 birds and 0 if otherwise;

The error term is assumed to follow the extreme value $(0,1)$ distribution, and as a result the probability that consumer $i$ chooses alternative $j$ in choice set $s$ follows the multinomial logit model:

$$
\operatorname{Pr}\left(y_{i s}=j\right)=\frac{\exp \left(u_{i j}\right)}{\sum_{j=1}^{J} \exp \left(u_{i j}\right)}
$$

The model development so far has focused on a given individual. The preference is expected to vary across individuals. The heterogeneous preference across individuals is captured in Equation (3), where the individual preference parameters $\beta_{i}$ 's are assumed to follow a multivariate normal distribution with mean $\bar{\beta}$ and variance-covariance matrix $\Delta$.

$$
\beta_{i} \sim \operatorname{Normal}(\bar{\beta}, \Delta)
$$

Model-based inference. The average preference estimates $(\bar{\beta})$ are reported in Table 4 . For the purpose of parameter identification, we set preference for egg feed origin in USA to zero. Relative preferences for feed origin from China and Argentina are significantly negative from zero at the $1 \%$ level. In another word, on average, consumers prefer the eggs with feed from USA more than from either China or Argentina. When feed origin information is missing, its preference is not significantly different that with feed origin in USA. A closer look at the distribution of the heterogeneity for this attribute (see Figure 1) reveals that the distribution of $\beta_{i, \text { OriginND }}$ resembles the shape of the mixture of two Normal distributions. About one fourth (26.9\%) of consumers belong to a segment that are skeptical and have a negative view about the feed origin when it is missing, manifested by the left portion of the curve peaking on the negative side. The right part of the distribution with a small peak on the positive side indicates that a small proportion $(17.7 \%)$ of consumers have a positive view of the missing origin. The preference of the majority of consumers (55.4\%) for 
the eggs with missing information on feed origin is not significant from zero. It is likely that these consumers assume the missing feed origin information indicates the feed comes from the USA. Another interesting finding is that the preference magnitude for organic feed (0.84) is not as big as consumers' negative association towards eggs if the chicken's feed came from China (-1.76). In another word, eggs with organic feed from China are less favorable compared to eggs with non-organic feed from the USA.

\section{Figure 1: Study 1 - Distribution of Heterogeneity}

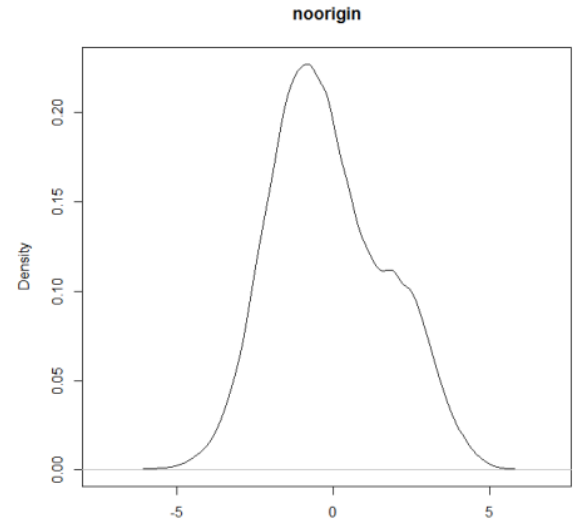

Table 4: Model Estimation Results

\begin{tabular}{lrr}
\hline \hline & Study 1 & Study 2 \\
\hline OriginND & $-0.44(0.20)$ & $-0.74 *(0.26)$ \\
OriginC & $-1.76 *(0.30)$ & $-1.46 *(0.28)$ \\
OriginA & $-0.95 *(0.19)$ & $-0.60 *(0.19)$ \\
Price & $-0.68 *(0.06)$ & $-0.64 *(0.07)$ \\
Organic feed & $0.84 *(0.20)$ & $0.63 *(0.19)$ \\
Cage-free & $1.53 *(0.15)$ & $1.57 *(0.14)$ \\
USDA & $0.00(0.27)$ & $-0.33(0.28)$ \\
SizeND & $0.71 *(0.12)$ & $0.51 *(0.14)$ \\
SizeSm & $0.48 *(0.12)$ & $0.33 *(0.13)$ \\
\hline \hline
\end{tabular}

Note: The table shows posterior means along with posterior standard deviations in parentheses.

* Indicates significance at the $1 \%$ level.

Contrary to the findings from extant literature that well-known certification logos of organic labeling are favored by consumers (Janssen and Hamm 2012; Kiesel and Villas-Boas 2007), the preference for USDA certification is found to be zero for these consumers when they choose organic eggs. The general pattern of preference estimates for other variables is as expected. Price negatively impacts the utility. For bird size, the missing information on bird size has a positive preference relative to bird size bigger than 10,000 birds, so does the small bird size (less than 10,000).
Market Simulation. To further assess the impact of feed origin information disclosure, we compared the market share of organic eggs when the feed origin information is missing vs. disclosed. Specifically, we want to understand if the sellers were to voluntarily disclose the feed origin of their organic eggs, what market share and price premium could be claimed after the voluntary disclosure compared to the original market situation when feed origin is missing. We computed brand shares under a fairly representative market scenario as shown in Table 5. Egg A is non-organic, non-cage free and lowest priced at $\$ 1.99 /$ dozen. Egg $B$ is non-organic, but cage-free. It is priced at $\$ 2.99 /$ dozen. Egg $\mathrm{C}$ is USDA organic, cage-free and most expensively priced at $\$ 4.99 /$ dozen. In Scenario 1 (baseline scenario), the information on feed origin is missing for Egg A, B and C. The market shares for A, B and C are $21.14 \%, 49.46 \%$ and $29.40 \%$ respectively. In Scenario 2, when the feed origin of egg $\mathrm{C}$ is changed to USA, the market shares for $\mathrm{A}, \mathrm{B}$ and $\mathrm{C}$ are $18.18 \%, 42.54 \%$ and $39.27 \%$. The share of organic egg is increased by about $10 \%$ when the feed origin is labeled as coming from the USA from when the feed origin in unknown. The increase in egg C's market share mainly comes from the middle tiered egg (egg B), which witnessed a loss of about $7 \%$ in share. The price premium that egg $\mathrm{C}$ could charge is $\$ 0.65 /$ dozen if the feed from USA is labeled compared to the baseline situation when the feed origin information is missing. The price premium is calculated assuming that the market share in Scenario 2 is not changed from the baseline scenario. In another word, if the same market share were to be maintained at the same level as the baseline scenario, Egg C could claim a higher price of $\$ 0.65 /$ dozen when the feed origin information for organic eggs is changed from missing to from the USA. Finally, in Scenario 3, when the feed origin of egg $\mathrm{C}$ is changed to China, the market shares for $\mathrm{A}, \mathrm{B}$ and $\mathrm{C}$ are $26.95 \%, 63.04 \%$ and $10.01 \%$. While egg $\mathrm{B}$ (share increased by $13.58 \%$ compared to baseline) is the bigger beneficiary of the egg C's market share decline (decreased by $19.39 \%$ compared to baseline), some egg $\mathrm{C}$ buyers even switched to egg A (share increased by $5.81 \%$ ). Egg $\mathrm{C}$ with feed imported from China would have to discount by $\$ 1.94 /$ dozen if the feed origin information is labeled in order to maintain the same market share. In addition, policy makers would be interested to know the market impact of a mandatory disclosure of feed origin. If under a situation where all the feed origin is a mandated disclosure, the price premium of USA feed over Chinese feed is $\$ 2.59 /$ dozen (difference between Scenario 2 and Scenario 3 ).

\section{Table 5: Study 1 Market Simulation}




\begin{tabular}{|c|c|c|}
\hline $\operatorname{Egg} A$ & Egg B & Egg C \\
\hline \multicolumn{3}{|c|}{ Scenario 1 (baseline) } \\
\hline Price: $\$ 1.99 /$ dozen & Price: $\$ 2.99 /$ dozen & Price: $\$ 4.99 /$ dozen \\
\hline Non organic feed & Non organic feed & Organic feed \\
\hline Non cage-free & Cage-free & Cage-free \\
\hline Non USDA & Non USDA & USDA \\
\hline Size: not disclosed & Size: not disclosed & Size: not disclosed \\
\hline Feed origin: Missing & Feed origin: Missing & Feed origin: Missing \\
\hline Market share: $21.14 \%$ & Market share: $49.46 \%$ & Market share: $29.40 \%$ \\
\hline \multicolumn{3}{|c|}{ Scenario 2 (USA) } \\
\hline Feed origin: Missing & Feed origin: Missing & Feed origin: US A \\
\hline Market share: $18.18 \%$ & Market share: $42.54 \%$ & Market share: $39.27 \%$ \\
\hline \multicolumn{3}{|c|}{ Scenario 3 (China) } \\
\hline Feed origin: Missing & Feed origin: Missing & Feed origin: China \\
\hline Market share: $26.95 \%$ & Market share: $63.04 \%$ & Market share: $10.01 \%$ \\
\hline
\end{tabular}

In summary, Study 1 finds evidence that the information on feed origin is an important factor in people's purchase decision of eggs, more so than organic feed and USDA certification label. Without a mandatory disclosure policy, a small price premium ( $\$ 0.65 /$ dozen) can be potentially claimed by labeling the feed from USA. However, the preference of missing information on feed origin is not significantly different from the preference of feed from USA. Sellers of the eggs with feed from non-USA countries should be motivated to disguise the information on feed origin. If the policy makers mandate the disclosure of feed origin, the USA feed could claim a much bigger price premium $(\$ 2.59 /$ dozen $)$ over the least popular feed origin in the study.

\subsection{Study 2}

Study Design. Study 1 represents the current market situation in which feed origin is not required to disclose, but companies may choose to disclose it. The findings from Study 1 show that eggs with feed from USA have a competitive edge compared to eggs with feed from China and Argentina. At the same time, not labeling the feed origin from non-USA countries would not hurt the sales of the corresponding eggs. In the current market situation where the labeling of feed origin is not mandated, the producers and retailers of eggs with USA feed won't benefit much from labeling the feed origin. Consumers' welfare will be undermined if they do want eggs with feed from the USA but end up buying eggs with missing feed origin information. However, as we discussed earlier, a mandatory disclosure could take a long time to become a policy. Increasingly, consumers are becoming more reliant on third party product information platforms to find out more information about products. In Study 2, we explore a way for the third party product information platforms to more effectively signal the unavailability of the missing information on feed origin.

To make the results comparable with those of Study 1, we again used egg as focal product category in Study 2. The data was again collected using a Qualtrics web-based survey and a nationwide online sample. 130 respondents (a different sample from Study 1) participated in Study 2. The attributes and levels used in the conjoint exercises are the same with those in Study 1. The only difference is that the undisclosed feed origin is labeled literally as "Feed origin is not disclosed" instead of missing, shown in Table 6. It has been found that consumers tend to rely on information that is more salient, and information presentation can be used to highlight meaning that is less salient on its own [34]. Displaying "Feed origin is not disclosed" could raise the salience of this attribute level and potentially help consumers distinguish the feed that comes from USA vs. undisclosed feed origin. Study 2 participants have similar demographic background to Study 1 respondents too.

Table 6: An Example of the Conjoint Exercise in Study 2

\begin{tabular}{|l|l|l|}
\hline $\boldsymbol{E g} \boldsymbol{g} \boldsymbol{A}$ & $\boldsymbol{E} \boldsymbol{g} \boldsymbol{B}$ & $\boldsymbol{E} \boldsymbol{g} \boldsymbol{C}$ \\
\hline $\begin{array}{l}\text { Price: } \\
\$ 3.99 / \text { dozen }\end{array}$ & $\begin{array}{l}\text { Price: } \\
\$ 4.99 / \text { dozen }\end{array}$ & $\begin{array}{l}\text { Price: } \\
\text { \$2.99/dozen }\end{array}$ \\
\hline Organic feed & Organic feed & Non organic feed \\
\hline $\begin{array}{l}\text { Hens are raised in } \\
\text { cages }\end{array}$ & $\begin{array}{l}\text { Hens are raised } \\
\text { cage free }\end{array}$ & $\begin{array}{l}\text { Hens are raised } \\
\text { cage free }\end{array}$ \\
\hline $\begin{array}{l}\text { No USDA } \\
\text { Organic } \\
\text { certification }\end{array}$ & $\begin{array}{l}\text { USDA Organic } \\
\text { certification }\end{array}$ & $\begin{array}{l}\text { No USDA } \\
\text { Organic } \\
\text { certification }\end{array}$ \\
\hline $\begin{array}{l}\text { Size: } 10,000- \\
100,000 \text { birds }\end{array}$ & $\begin{array}{l}\text { Size: } 100,000- \\
\text { 250,000 birds }\end{array}$ & $\begin{array}{l}\text { Flock size is not } \\
\text { disclosed }\end{array}$ \\
\hline $\begin{array}{l}\text { Feed origin is } \\
\text { not disclosed }\end{array}$ & $\begin{array}{l}\text { Feed comes from } \\
\text { Argentina }\end{array}$ & $\begin{array}{l}\text { Feed comes from } \\
\text { USA }\end{array}$ \\
\hline
\end{tabular}

Model-based inference. The average preference estimates $(\bar{\beta})$ in Study 2 are reported next to Study 1 results in Table 4 . The overall pattern of the preference is similar to Study 1 except for the undisclosed feed origin. The preference for undisclosed feed origin is significantly negative from zero in Study 2, whereas it is not significant when the information of feed origin is missing in Study 1. Analysis on heterogeneity reveals that $37.7 \%$ of respondents have a negative opinion of the undisclosed feed origin, an increase of more than ten percent from $26.9 \%$ in Study 1. The new information disclosure method that specifies the unavailable information on feed origin as "not disclosed" rather than missing makes the feed origin from USA much more appealing in comparison. It is noteworthy that average consumers' negative association towards eggs if the chicken's feed comes from a "not disclosed" location (-0.74) overwhelms the 
preference magnitude for organic eggs (0.63). It implies that all others equal, an average consumer would prefer eggs with non-organic feed coming from USA to eggs with organic feed coming from a "not disclosed" location.

Market Simulation. Similar to Study 1, we compare the market share of eggs when the feed origin information is "not disclosed" vs. disclosed in order to assess the impact of this new feed origin information disclosure method. The market simulation is computed under a fairly representative market scenario as shown in Table 7. Egg A is non-organic, non-cage free and lowest priced at $\$ 1.99 /$ dozen. Egg B is non-organic, but cage-free. It is priced at $\$ 2.99 /$ dozen. Egg C is USDA organic, cage-free and most expensively priced at $\$ 4.99 /$ dozen. In Scenario 1 (baseline scenario), the information on feed origin is "not disclosed" for Egg $\mathrm{A}, \mathrm{B}$ and $\mathrm{C}$. The market shares for $\mathrm{A}, \mathrm{B}$ and $\mathrm{C}$ are $22.29 \%, 56.50 \%$ and $21.21 \%$ respectively. In Scenario 2 , when the feed origin of the organic egg $\mathrm{C}$ is changed to USA, the market shares for A, B and C are $18.09 \%$, $45.85 \%$ and $36.06 \%$. The share of the organic eggs is increased by about $15 \%$ from scenario 1 to 2 . The increase in egg C's market share mainly comes from egg B, which witnesses a loss of about $11 \%$ in share. The price premium that egg $\mathrm{C}$ could charge is $\$ 1.16 /$ dozen if the feed from USA is labeled compared to "not disclosed" feed origin. Similar to Study 1, the price premium is calculated assuming that the market share in Scenario 2 is not changed from the baseline scenario. The higher price premium that egg $\mathrm{C}$ with USA feed could claim in comparison to that in Study 1 (\$1.16 vs. \$0.65 per dozen) signifies the power of the new information disclosure method. Finally, in Scenario 3, when the feed origin of egg $\mathrm{C}$ is changed to China, the market shares for A, B and C are $25.02 \%$, $63.40 \%$ and $11.58 \%$. Egg $\mathrm{C}$ with feed imported from China would have to discount by $\$ 1.13 /$ dozen if the feed origin information is labeled.

Study 2 tests an information sharing method for the third party product information platform to effectively signal the unavailability of the missing information on feed origin, when mandatory disclosure is not in place. The goal is to find an inexpensive way to reduce the harm caused by information asymmetry, so that consumers could pay more attention to the missing information on feed origin when they shop for organic eggs. With the feed origin shown as "not disclosed" instead of feed origin information being omitted for those non-disclosures on feed origin, the eggs with feed from USA are much more preferred by consumers and hence could charge a much higher price premium.

Table 7: Study 2 Market Simulation

\begin{tabular}{|c|c|c|}
\hline $\operatorname{Egg} A$ & Egg B & Egg C \\
\hline \multicolumn{3}{|c|}{ Scenario 1 (baseline) } \\
\hline Price: $\$ 1.99 /$ dozen & Price: $\$ 2.99 /$ dozen & Price: $\$ 4.99 /$ dozen \\
\hline Non organic feed & Non organic feed & Organic feed \\
\hline Non cage-free & Cage-free & Cage-free \\
\hline Non USDA & Non USDA & USDA \\
\hline Size: not disclosed & Size: not disclosed & Size: not disclosed \\
\hline $\begin{array}{l}\text { Feed origin: Not } \\
\text { disclosed }\end{array}$ & $\begin{array}{l}\text { Feed origin: Not } \\
\text { disclosed }\end{array}$ & $\begin{array}{l}\text { Feed origin: Not } \\
\text { disclosed }\end{array}$ \\
\hline Market share: $22.29 \%$ & Market share: $56.50 \%$ & Market share: $21.21 \%$ \\
\hline \multicolumn{3}{|c|}{ S cenario 2 (USA) } \\
\hline $\begin{array}{l}\text { Feed origin: Not } \\
\text { disclosed }\end{array}$ & $\begin{array}{l}\text { Feed origin: Not } \\
\text { disclosed }\end{array}$ & Feed origin: US A \\
\hline Market share: $18.09 \%$ & Market share: $45.85 \%$ & Market share: $36.06 \%$ \\
\hline \multicolumn{3}{|c|}{ Scenario 3 (China) } \\
\hline $\begin{array}{l}\text { Feed origin: Not } \\
\text { disclosed }\end{array}$ & $\begin{array}{l}\text { Feed origin: Not } \\
\text { disclosed }\end{array}$ & Feed origin: China \\
\hline Market share: $25.02 \%$ & Market share: $63.40 \%$ & Market share: $11.58 \%$ \\
\hline
\end{tabular}

\section{Discussion \& Concluding Remarks}

In summary, our study found that revealing feed origin makes a difference in consumers' choice of organic eggs. Eggs with feed from US have a competitive advantage over eggs with feed from China or Argentina. However, we were also able to illustrate that in a current market situation in which there is no requirement to disclose feed origin, seller are more often than not motivated to hide this information away from consumers. When feed origin is omitted from the label, eggs with non-US origin received similar preference to eggs with US feed origin. Assumingly, farmers in US are in general under more stringent legal requirement and thus are assumed by consumers of delivering higher quality of organic eggs. At the same time, meeting higher level quality requirements might also incur higher level of production cost. While not adequately compensated by the market, there might be little motivation for producers to pursue higher level of quality, leading to market failure. At the same time, consumers' confidence and trust over organic certification regulation might be eroded over the time if they assumed of buying organic product with consistent and high quality while end up getting product with questionable quality.

Our study demonstrated that this problem can be potentially corrected in two ways. The first approach is to mandate the disclosure of feed origin, and the second is to utilize a food traceability and disclosure platform that heighten the salience of feed origin. Government may require that firms producing goods with credence or potemkin attributes to substantiate their claims through mandatory labeling or disclosure system. This approach, although effective, requires major legislative actions, which may encounter substantial resistance in the short term. The difficulties 
can be illustrated by the recent failure of passing a bill that would have set labeling standards for genetically modified foods based on arguments of protecting firms and consumers from raising costs and other interests. In US, food traceability systems that include feed origin have been largely motivated by economic incentives, rather than government regulation [35]. Although private sectors have developed enormous capability to track the flow of food, government has refrained from imposing traceability and disclosure standards to private entities, under the assumption that private will be motivated to disclose by benefits of expanded sales of high-value products. This study, however, proved that this assumption may not be correct. The policy implications of a mandated disclosure regulation may need to be revisited in light of the empirical results. The second approach, what we called "smart disclosure", will reach similar desirable results by establishing guidelines for third-party platforms that raise the salience of missing information on feed origin. This might be a more realistic and low cost approach. Our study 2 illustrated that under this approach, even when the sellers are under no obligations to reveal feed origin, the stated omission of information became a salient variable, and will be treated with greater scrutiny from consumers. Consumers' informed decisions in turn will unleash the power of the market, and provide incentives for sellers to reveal validating cues, such as US feed origin, to gain additional market share or claim higher premium. As such, our study thus provide important directions for smart disclosure policy initiatives.

In addition, it also has policy implications for achieving sustainable consumption. In recent years, sustainability became a raising issue and the government roles in guiding consumption patterns toward a more sustainable way are particularly highlighted [25]. This paper introduced an approach by which public and private sector can determine what information is effective, and how information can be consequential in reaching the policy goals for a more sustainable pattern of consumption and production. By focusing on the feed origin of organic eggs, we discover that with an effective disclosure on feed origin, the US farmers might be at a better position to take advantage of the potential price premium over the imported feed and be more motivated to convert into organic farming, which delivers greater benefits to environment and local economy.

This research made important contribution to theory for sustainability policy approaches. In reent years, an approach in the form of regulation through information [36], informational regulation and information governance [37] that emphasizes the role of creation, processing, dissemination, and utilization of information in environmental regulations has emerged. It has been observed that regulations that require private entities to disclose information lead to desirable outcomes, such as with the emission of toxic chemicals [38]. The use of information as a policy instrument is seen as promising because it enlists the market forces to create demand for firms to pursue environmental interests as a results of their connection to financial outcomes in the market. Information as a governance instrument to address social and environmental goals in future generations has received increasing attention from the e-government research (Estevez \& Janowski, 2013). This study extends the understanding of information regulation in the context of consumer decision making in organic market. More importantly, it also revealed the limitation of such approach if it relies merely on voluntary disclosure. It appears that a combined approach that join regulatory mandates with information disclosure would be more effective. This might be a direction for more studies in the future.

Finally, this research has limitations. First, we made feed origin as the focus of this paper as an illustration of our approach. More systematic evaluation of organic product attributes could be conducted by using similar approach to provide comprehensive guidelines for organic product information disclosure. Second, we find feed origin an important attribute in organic egg purchase and consumers prefer US feed. Future study should focus on the rationale and investigate the causes of the feed origin preference to provide more diagnostic suggestions for public and private sectors.

\section{References}

[1] C. R. Sunstein, G. Loewenstein, and R. Golman, "Disclosure: Psychology Changes Everything," 2014.

[2] G. Akerlof, The market for "lemons": Quality uncertainty and the market mechanism: Springer, 1995.

[3] S. A. Ross, "The economic theory of agency: The principal's problem," The American Economic Review, vol. 63, no. 2, pp. 134-139, 1973.

[4] O. Ben-Shahar, and C. E. Schneider, "The failure of mandated disclosure," University of Pennsylvania Law Review, pp. 647-749, 2011.

[5] R. H. Thaler, and W. Tucker, "Smarter information, smarter consumers," Harvard Business Review, vol. 91, no. 1, pp. 44-54, 2013.

[6] R. E. Nisbett, and L. Ross, "Human inference: Strategies and shortcomings of social judgment," 1980.

[7] D. Tilman, K. G. Cassman, P. A. Matson, R. Naylor, and S. Polasky, "Agricultural sustainability and intensive production practices," Nature, vol. 418, no. 6898, pp. 671-677, 2002. 
[8] K. Giannakas, "Information asymmetries and consumption decisions in organic food product markets," Canadian Journal of Agricultural Economics/Revue Canadienne D'Agroeconomie, vol. 50, no. 1, pp. 35-50, 2002.

[9] C. Liu, "Is USDA Organic a Seal of Deceit: The Pitfalls of USDA Certified Organics Produced in the United States, China and Beyond," Stan. J. Int'l L., vol. 47, pp. 333, 2011.

[10] Organic Trade Association, State of the Industry, 2014.

[11] S. Daniells, "US organic food market to grow $14 \%$ from 2013-18," FoodNavigator-USA. com, vol. 3 , 2014.

[12] B. H. Lee, "The infrastructure of collective action and policy content diffusion in the organic food industry," Academy of Management Journal, vol. 52, no. 6, pp. 1247-1269, 2009.

[13] J. Forman, J. Silverstein, J. J. Bhatia, S. A. Abrams, M. R. Corkins, S. D. de Ferranti, N. H. Golden, J. A. Paulson, A. C. Brock-Utne, and H. L. Brumberg, "Organic foods: health and environmental advantages and disadvantages," Pediatrics, vol. 130, no. 5, pp. e1406-e1415, 2012.

[14] USDA, "List of USDA-Authorized Organic Certifying Agents by Name," 2015.

[15] J. Henryks, D. Pearson, T. Anisimova, and P. Sultan, "Are organic food labels inadequate? Evidence from consumers in Australia," Business and Management Studies, vol. 1, no. 2, pp. 45-54, 2015.

[16] J. Gabriele, M. Schramm, and A. Spiller, "The reliability of certification: Quality labels as a consumer policy tool," Journal of Consumer Policy, vol. 28, pp. 53-73, 2005.

[17] Joint FAO/WHO Codex Alimentarius Commission, and W. H. Organization, Organically produced foods: Food \& Agriculture Org., 2007.

[18] C. R. Sunstein, "Empirically informed regulation," The University of Chicago Law Review, vol. 78, no. 4, pp. 1349-1429, 2011.

[19] J. Cobb, "Smart disclosure: Innovation in personal data," Spruce Advisers, 2012.

[20] J. Zhang, H. Liu, D. S. Sayogo, S. Picazo-Vela, and L. Luna-Reyes, "Strengthening institutional-based trust for sustainable consumption: Lessons for smart disclosure," Government Information Quarterly, 2016.

[21] J. E. Hermansen, "Organic livestock production systems and appropriate development in relation to public expectations," Livestock production science, vol. 80, no. 1, pp. 3-15, 2003.

[22] V. Owusu(1)a, and M. O. Anifori, "Consumer willingness to pay a premium for organic fruit and vegetable in Ghana," International Food and Agribusiness Management Review, vol. 16, no. 1, 2013.

[23] D. Pearson, J. Henryks, P. Sultan, and T. Anisimova, "Organic food: Exploring purchase frequency to explain consumer behaviour," Journal of Organic Systems, vol. 8, no. 2, pp. 50-63, 2013.
[24] C. K. Winter, and S. F. Davis, "Organic foods," Journal of food science, vol. 71, no. 9, pp. R117R124, 2006.

[25] J. Thøgersen, "How may consumer policy empower consumers for sustainable lifestyles?," Journal of Consumer Policy, vol. 28, no. 2, pp. 143-177, 2005.

[26] R. Schleenbecker, and U. Hamm, "Consumers' perception of organic product characteristics. A review," Appetite, vol. 71, pp. 420-429, 2013.

[27] H. H. Bauer, D. Heinrich, and D. B. Schäfer, "The effects of organic labels on global, local, and private brands: More hype than substance?," Journal of Business Research, vol. 66, no. 8, pp. 1035-1043, 2013.

[28] S. Eden, "Business, trust and environmental information: Perceptions from consumers and retailers," Business Strategy and the Environment, vol. 3, no. 4, pp. 1-8, 1994.

[29] A. Enger, and R. Lavik, "Eco-labelling in Norway: consumer knowledge and attitudes." pp. 479-502.

[30] H. Stolz, H. Moschitz, and M. Janssen, "Organic certification labels from the perspective of consumers in Switzerland," Yearbook of Socioeconomics in Agriculture, vol. 2013, pp. 225246, 2013.

[31] M. Janssen, and U. Hamm, "Product labelling in the market for organic food: Consumer preferences and willingness-to-pay for different organic certification logos," Food Quality and Preference, vol. 25, no. 1, pp. 9-22, 2012.

[32] K. Kiesel, and S. B. Villas-Boas, "Got organic milk? Consumer valuations of milk labels after the implementation of the USDA organic seal," Journal of agricultural \& food industrial organization, vol. 5, no. 1, 2007.

[33] P. E. Green, and V. R. Rao, "Conjoint measurement for quantifying judgmental data," Journal of Marketing research, pp. 355-363, 1971.

[34] J. H. Hibbard, and E. Peters, "Supporting informed consumer health care decisions: data presentation approaches that facilitate the use of information in choice," Annual Review of Public Health, vol. 24, no. 1, pp. 413-433, 2003.

[35] E. H. Golan, B. Krissoff, F. Kuchler, L. Calvin, K. Nelson, and G. Price, Traceability in the US food supply: economic theory and industry studies: US Department of Agriculture, Economic Research Service Washington, DC, 2004.

[36] W. M. Sage, "Regulating through information: disclosure laws and American health care," Columbia Law Review, pp. 1701-1829, 1999.

[37] A. P. Mol, "Environmental governance in the Information Age: the emergence of informational governance," Environment and planning C, vol. 24, no. 4, pp. 497, 2006.

[38] M. Khanna, "Non-mandatory approaches to environmental protection," Journal Of Economic Surveys, vol. 15, no. 3, 2001. 